Technical note

\title{
Urban railway traffic noise: Looking for the minimum cost for the whole community
}

\author{
Guido J.L. Micheli ${ }^{a, *}$, Stefano Farné ${ }^{b}$ \\ "Politecnico di Milano, Department of Management. Economics and Industrial Engineering, Piazza Leonardo da Vinci 32, 20133 Milan, Italy
}

${ }^{b}$ Università degli Studi di Pavia, Department of Industrial Engineering and Information Technology. Via A. Ferrata 5, 27100 Pavia, Italy

\section{A R T I C L E I N F O}

\section{Article history:}

Received 2 November 2015

Received in revised form 21 May 2016

Accepted 21 June 2016

\section{Keywords: \\ Railway \\ Noise \\ Urban \\ Cost \\ Community \\ Trade-off}

\section{A B S T R A C T}

Nowadays, railway traffic noise is acknowledged to negatively impact the wellbeing of the whole community, particularly in urban environments. Unfortunately, the traditional approach to support decision making in noise reduction intervention seems to start only from the compliance to the regulations in place, rather than from the identification of an optimal trade-off between the cost of the annoyance of the community and the cost of the intervention. An advanced approach is proposed, which starts from any annoyance due to traffic noise, and which aims at identifying an optimal trade-off by means of evaluation of the minimum cost for the whole community. A case study in a railway noise-affected urban cluster of Milan, Italy, has been performed, which is representative of any urban environment affected by traffic noise. The sensitivity analysis on the parameters of the approach (the size of the buildings; the level of railway traffic; the cost per square meter of the acoustic barriers) shows that the results are robust and reliable, and in the specific case a noise reduction of $15-25 \mathrm{~dB}$ is optimal for the community.

(c) 2016 Elsevier Ltd. All rights reserved. 


\title{
Urban railway traffic noise: Looking for the minimum cost for the whole community
}

\author{
Guido J.L. Micheli ${ }^{a}{ }^{\star}$, Stefano Farnéb \\ a Politecnico di Milano, Department of Management, Economics and Industrial Engineering, Piazza Leonardo \\ da Vinci 32, 20133 Milan, Italy \\ b Università degli Studi di Pavia, Department of Industrial Engineering and Information Technology, Via A. \\ Ferrata 5, 27100 Pavia, Italy
}

\author{
* Corresponding author. \\ E-mail address: guido.micheli@polimi.it
}

\begin{abstract}
Nowadays, railway traffic noise is acknowledged to negatively impact the wellbeing of the whole community, particularly in urban environments. Unfortunately, the traditional approach to support decision making in noise reduction intervention seems to start only from the compliance to the regulations in place, rather than from the identification of an optimal trade-off between the cost of the annoyance of the community and the cost of the intervention. An advanced approach is proposed, which starts from any annoyance due to traffic noise, and which aims at identifying an optimal trade-off by means of evaluation of the minimum cost for the whole community. A case study in a railway noise-affected urban cluster of Milan, Italy, has been performed, which is representative of any urban environment affected by traffic noise. The sensitivity analysis on the parameters of the approach (the size of the buildings; the level of railway traffic; the cost per square meter of the acoustic barriers) shows that the results are robust and reliable, and in the specific case a noise reduction of 15 to $25 \mathrm{~dB}$ is optimal for the community.
\end{abstract}

Keywords: Railway, noise, urban, cost, community, trade-off.

\section{Introduction}

Noise is a considerable social problem as it can be considered a kind of urban pollution. The transport sector is one of the main contributors to society's noise problem, and the combination of increasing traffic volume and urbanization implies that the problem would increase if no measures were taken to stem it $[1,2,3]$. Road traffic is the largest single source of noise in the transport sector, but other means such as aircraft and trains substantially contribute to noise emissions too [3, 4]. It is estimated that more than $20 \%$ of the EU's population are exposed to higher levels of noise than those deemed acceptable [5]. The estimates of the European 
population continuously exposed to values higher than $55 \mathrm{~dB}$, from rail traffic, fluctuate from $10 \%$ [6] to over $44 \%$ [7], highlighting a widespread phenomenon with potentially negative effects of different extents and natures $[7,8,9]$. Recent investigations indicate that railway noise leads to significant sleep fragmentation and cardiovascular activations during sleep, and to subjective distress, as well as long-term effects of prolonged exposure to noise [10]. The study by the World Health Organization (WHO) (Regional Office for Europe, NIGHT NOISE GUIDELINES FOR EUROPE), issued in 2009 [9], indicates that "considering the scientific evidence on the thresholds of night noise exposure indicated by Lnight,outside as defined in the Environmental Noise Directive (2002/49/EC), an Lnight,outside of $40 \mathrm{~dB}$ should be the target of the night noise guideline (NNG) to protect the public, including the most vulnerable groups such as children, the chronically ill and the elderly. Lnight,outside value of $55 \mathrm{~dB}$ is recommended as an interim target for the countries where the NNG cannot be achieved in the short term for various reasons, and where policy-makers choose to adopt a stepwise approach". Moreover, the WHO estimates that more than 1 million healthy life years are lost every year in western Europe due to noise exposure [11]. In order to quantitatively evaluate the impact of noise on the exposed population, some methods of quantification of the disorder (or annoyance) are known [12], as for example, in [3, 4].

Despite the magnitude of the effects of noise, the Italian legislation $[13,14]$ and the literature in general do not offer models for the quantification of the annoyance, nor do they offer useful methodologies to support decision-making about the possible remediation interventions (i.e., interventions to reduce the acoustic impact). These limitations are reflected in the approaches that are traditionally used to establish the means of intervention to reduce noise in an urban context; they are characterized by the fact that:

1. The need for intervention arises only from the requirements and not by the discomfort actually suffered by the community. This means that, in situations where the law is flawed and does not work properly, the possibility of any intervention of noise abatement is not considered;

2. If the legislation obliges to take action to reduce the noise, the criterion to choose the best of several possible interventions is the minimum cost. In other words, the cost curves of the different interventions are taken into consideration and, at equal levels of noise abatement, the one that presents the minimum cost of implementation is chosen. This means that the intervention often aims at reducing the sound level to an acceptable level (within the parameters of law), without taking into account the benefits that a further reduction could bring to the community.

On the other hand, the growing attention to the problem in Europe [15], with reference to the railway [16, 17], highlights the need to overcome the legislative approach in favour of methodologies based also on finding a trade-off between costs and benefits deriving from an intervention.

\subsection{The possible interventions to reduce the acoustic impact}

The negative effects of noise may be reduced through legislation, by means of requirement of less noisy technology, or by investments, such as noise barriers, or by sanctions that punish noisier vehicles and lead to a reduction of the noise level. Noise-reducing measures often result in a cost, for instance longer travelling times or costs of physical measures such as noise barriers and façade insulation [18, 19]. This, and the fact that society also faces other needs, implies that a form of prioritization must be defined when it is necessary 
to decide on resource allocation. Benefit-cost analysis (BCA) is a potential basis for decision making, but it requires both benefits and costs to be measured in a common metric.

\subsection{Noise: characteristics, social costs and evaluation}

The issue about health problems raises the question of whether people are informed about the negative health effects and their costs when they reveal their willingness to pay (WTP) in order to reduce their noise exposure. If not, this needs to be taken into account when the benefit measures have to be calculated. To estimate the social value of noise abatement we combine measures that reflect individuals' preferences to reduce the noise levels from a study of the hedonic property price with estimates for the social cost related to health effects from noise exposure.

The A-weighted sound pressure level, measured over $24-\mathrm{h}$ and usually denoted LAEq,24h, is often used as an indicator of noise levels. It is an energy mean level and it correlates well with the general annoyance due to noise at a given place. A more relevant measure for sleep disturbance is the maximum level combined with the number of occurrences (LAFmax). Different sources have different noise profiles over a 24-h period. Rail traffic sometimes has a higher proportion of freight trains running at night, and it is therefore not unusual for the equivalent level at night (22-06) to be higher than during the day (06-22). Rail traffic typically has a high maximum level compared to the equivalent level; that is, the individual passages are separated, with silent periods in between. The EU joint noise indicator LDEN is an attempt to balance the 24-h effects of traffic. This is, in principle, a weighted equivalent level where passages in the evening and at night are counted as $5 \mathrm{~dB}$ and $10 \mathrm{~dB}$ noisier, respectively, than is actually the case. Therefore, evening and night time noise are penalized, in the sense that they are given more weight in the model. The evaluation of annoyance due to traffic noise by means of questionnaires is often carried out on a 5-point scale, in accordance with ISO/TS 15666 [20]. One can also predict the number of people on the various annoyance levels according to [21], which is based on a meta-analysis of many studies [22]. Noise does not cause any direct environmental damage but incurs costs for society in the form of disturbances for the individual (sleep, conversation, recreation etc.), worsened health and loss of production. The latter may be due to absence from work or reduced capacity to work, or that if a person doesn't sleep well at night, he is consequently less productive than usual. The social costs of noise exposure may be divided into three groups (e.g. [23]):

1. Resource costs in the form of medical and health care. Includes costs financed by taxes and direct payments by the individual.

2. Opportunity costs in the form of loss of production. Includes "non-market services" carried out in the household and lost recreation time.

3. Dis-utility in the form of other negative influences resulting from noise exposure. Two examples are: the disturbances in different forms and the increased concern about the after effects as a result of exposure.

Dis-utility is estimated by means of the WTP approach, which is usually divided into two main groups depending on how the information is used. Preference estimates based on market data and hypothetical market situations are called "revealed preferences" (RP) and "stated preferences" (SP), where the notations show whether the actual or hypothetical choice is used. If individuals in the WTP studies were fully informed 
of the total cost of noise exposure and if they themselves would bear the costs completely, the values from such studies would reflect the social costs in the form of $\mathrm{COI}$ as well. The great majority of the WTP studies to elicit preferences for noise abatement has employed the RP approach using the hedonic price regression technique [24]. The "noise sensitivity depreciation index" (NSDI) has evolved as the standard measure of the WTP of this literature. This is a measure of the percentage change in the price as a result of a unit change in the noise level [25]. The EU project HEATCO [26], carried out in several European countries, was aimed at estimating the WTP to reduce noise from road and railway traffic.

The evaluation technique used to derive monetary values for noise annoyance can be based on the hedonic regression method [27]: the estimates are based on the price data from the property market and, according to the hedonic method, the price $(P)$ becomes a function of the various attributes that constitute the property,

$P=P(L, A)$

where $L$ denotes the noise attribute railway and $A=\left[a_{1}, \ldots, a_{n}\right]$ a vector with other attributes. Let $p i, i \in\{1,2\}$, denote the marginal WTP for a reduction of the noise level from source $i$, which is given by,

$\mathrm{pi}=\partial \mathrm{P}(\mathrm{L}, \mathrm{A}) / \partial \mathrm{Li}$

Equation 2 gives the marginal WTP. To estimate the theoretically consistent welfare measure for non-marginal changes, the demand functions should be estimated. If we assume that WTP studies do not capture the total social cost from noise exposure, it happens that the values from these studies need to be adjusted so that also the health effects of noise are included. In the first place, noise causes increased stress and poor sleep quality that may lead to high blood pressure and a higher risk of cardiovascular diseases over time [28]. There is also evidence that prolonged noise exposure not only increases the risk of myocardial infarction but also stroke. Health costs should be evaluated by means of the impact pathway approach (IPA) since it is sanctioned in the EU. The total social cost can therefore be derived from a combination of WTP estimates from hedonic pricing studies with cost estimates for health effects.

With particular reference to rail transport, as reported by Brons, Nijkamp, Pels and Rietveld [29] the major studies on the subject, until early 2000 s, in $60 \%$ of cases used to refer to hedonic methods, and in the remaining $40 \%$ of the cases to budget or similar (Cost/Benefit Index, as for example in Oertli and Wassmer [30]); as earlier mentioned, these estimates are affected by a significant margin of uncertainty, mainly originated by neglecting the social costs related to the effects of noise pollution on health (which is, by the way, certified as an indissoluble link from a variety of sources, for example [31]).

Over the last 10 years, due to increased sensitivity to the problem, further studies on the economic impact of noise reduction were conducted: among them, we comment on two which are - on our view - particularly close to our scope, namely the paper by Swinburn, Hammer, and Neitzel [32], and the British DEFRA (Department for Environment, Food \& Rural Affairs) report [33]. In [32], the authors point out, based on a selection of primary studies and meta-analyses, the correlation between noise levels and risk of CHD (Coronary Heart Disease) and hypertension. Adopting several conservative estimates, they eventually provide the reader with an annual economic benefit of 19.5 \$ per person, for a reduction of exposure to noise of $5 \mathrm{~dB}$ if compared to the existing scenario (which considers 200 million US people exposed to a noise level > $58 \mathrm{~dB}$ ). However, given the geographic and demographic differences of the US territory compared to the European one (it would also be relevant, although neglected here for simplicity of exposition, the matter of the difference of the respective 
welfare systems), we consider the content of the British DEFRA report [33] closer to the scope of our research, and use and comment on it in the following.

Specifically referring to the rail traffic in [33], the noise-related marginal cost values per household per dB of variation are tabulated (Annex I, Table A1.2); in order to standardize the results to our case, we consider a family composed by 2.4 people [34] and the GBP/EUR exchange rate at 1.26. Being the population density of Lombardy (part of Italy, around 200 inhabitants $/ \mathrm{km}^{2}$ ) and England (part of UK, around 200 inhabitants $/ \mathrm{km}^{2}$ ) quite similar (both around 400 inhabitants $/ \mathrm{km}^{2}$ ), considering the less exposed area (see later in the paper, Table 6, area B) and neglecting the effects of sleep disorder (categorized "amenity") and lost productivity (Annex I, Table A1.4, and Annex IV of the DEFRA report), for a reduction from $72 \mathrm{~dB}$ to $52 \mathrm{~dB}$ of average daily sound pressure level, an annual saving of about $158 € /$ person can be estimated, significantly higher than the value proposed (of course, in a very different context) in [32].

However, there are a number of problems with this approach, unlike the hedonic one. The usage of resources (money and time) for the statistical survey(s) needed to minimize the degree of uncertainty is very high: only NGOs have means, authorization and availability for accurate data collection(s). In any case, the statistical results provide an "average response" instead of the ideal "individual response" (or "local" response, which is the real situation when dealing with the acoustics remediation interventions). Since the studies and databases in the field of noise pollution are relatively recent and measurement campaigns involve a considerable expense (for example, accurate measurement of sound pressure level along a several kilometers long urban line, typically for 24 hours), the economic impact assessments tend to be underestimated (by not taking into account some items); as an example, using the model proposed by DEFRA, if we would include the marginal costs of central sleep disorder, the annual savings for reduction of $20 \mathrm{~dB}$ may increase by over $200 \%$. Last but not least, this estimate still disregards the collective impact of the noise-related disease, which is in fact a burden even on the National Health Service.

\section{An innovative approach to support the decisions of acoustics remediation intervention}

To overcome the weak points highlighted, we propose the use of a methodology applied for the first time to a problem of acoustic reclamation. The steps of this method are schematically shown in Fig. 1. 


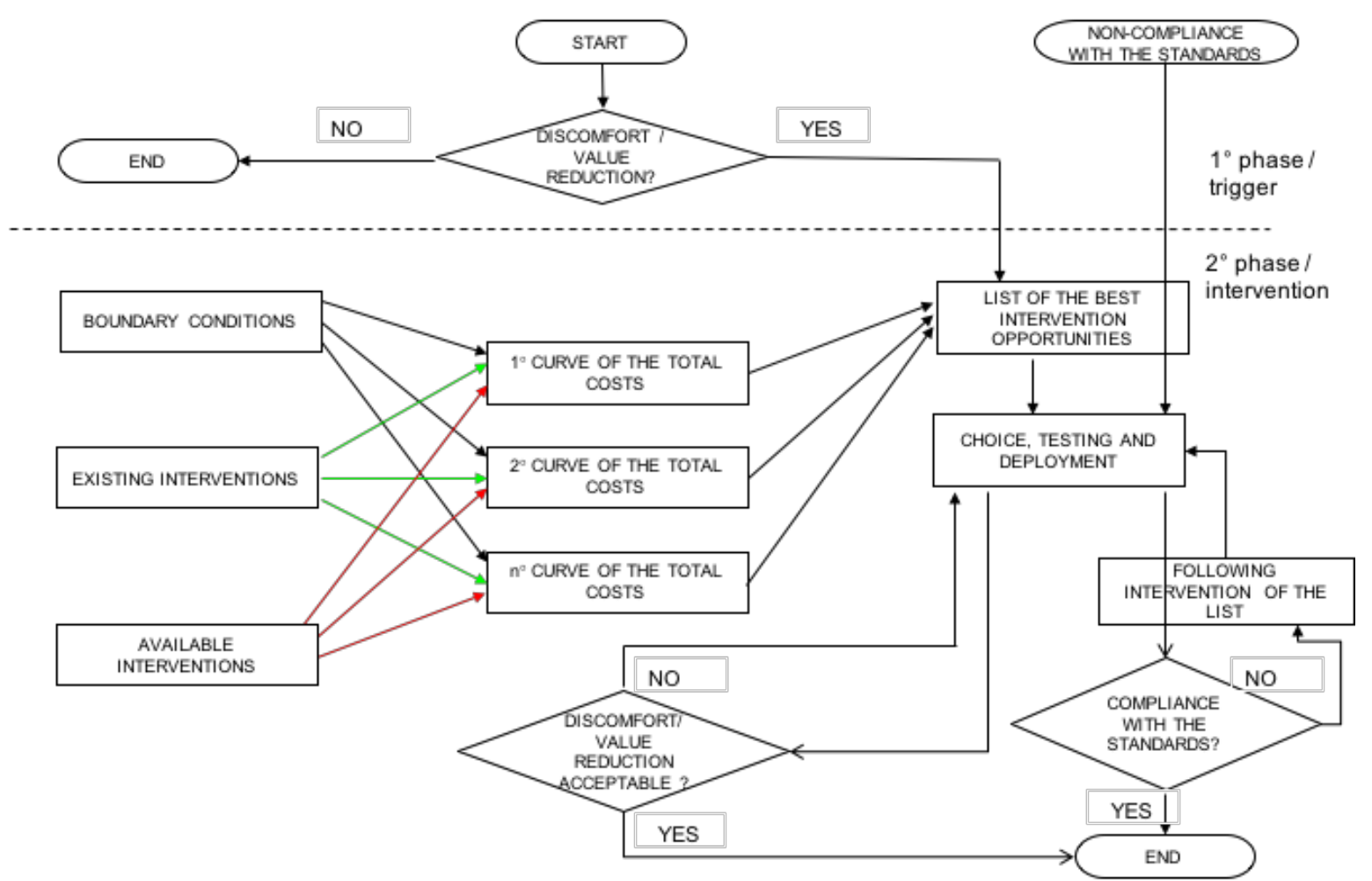

Fig. 1. Flow-chart of the representation of the acoustic intervention decisions

The two proposed innovations are highlighted in two distinct phases (Fig. 1) and, in particular: 1) The decision to make an intervention to reduce the noise can be generated not only by the need of compliance with the standards, but also by any condition of acoustic discomfort felt by the community. The intervention can therefore be justified mainly by two reasons, one social and the other one economic;

i) from the social perspective, the noise, although within the limits of the rules, can still cause discomfort to people, as is demonstrated by several scientific studies (among others, [7, 35, 36]);

ii) from the economic point of view, it is, moreover, known that acoustic discomfort, caused by noise, leads to a depreciation of the buildings located in an area affected by this phenomenon. The parameters that influence the value of a property, actually, are related to:

a) structure (number of rooms, presence of a garden etc.),

b) location (proximity to the centre of the town, proximity to public transportation etc.),

c) boundary conditions (presence of green, absence of noise, various services etc.) [37, 38];

2) The criterion adopted for the choice of intervention to be carried out is no longer that of the minimum cost of implementation, but that of the global optimum for the community. This means that not only the costs of the specific intervention are considered, but also the benefits that arise from the intervention through the construction of the total cost curve, which overall enables to find an absolute minimum of the total cost, carried out by the entire community. This curve is reported in Fig. 2 . 


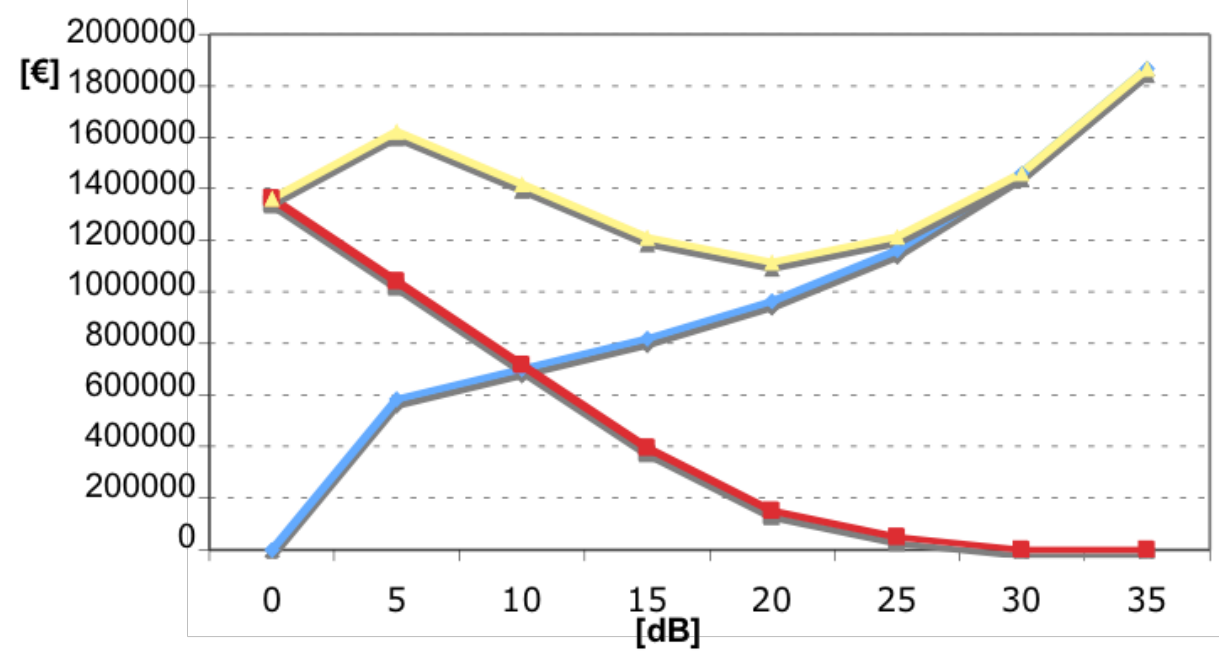

Legend:

cost of remediation: social cost:

Fig. 2. Generic representation of a total cost curve (vertical axis $€$ ) in function of the noise abatement (horizontal axis)

The breakdown of the three types of costs is the following.

- Cost of acoustic remediation: it refers to the burden that has to be supported to realize a particular intervention of noise abatement, which can be made at the source, at the receiver or on the way of propagation. This cost grows in a nonlinear manner with the growth of the noise abatement entity (in $\mathrm{dB}$ ). Its size is determined on the basis of the project intervention.

- Social cost of the noise: it refers to the reduction of psychophysical well-being (i.e. increase of the discomfort) of the people and to the depreciation of the value of the properties located in noisy areas. In Fig. 2, it is shown that when the noise reduction (dB) increases, also the benefits for the people grow. The determination of the monetary value due to the noise abatement can be done through the method of hedonic pricing [39].

- Total cost: the sum of the cost of acoustic remediation and of the social cost of the noise indicates the total cost due to each condition linked to intervention of noise reduction (including the condition of non-intervention, that is, with zero noise reduction). If there are several possible interventions, this cost would be the discriminating factor that will lead to the optimal choice of intervention.

\section{Research methodology: quantification of the noise exposure and of the associated costs}

The case study seems the most appropriate methodology to test the operation of the proposed approach in a real context, with a high degree of detail [40] and through the transversal study of the phenomenon. The unit of analysis is a defined environment, surrounding the railway track, in a densely populated urban area in the outskirts of Milan, the area where the trains have not the obligation to a significant lowering of speed yet; this 
unit is representative of any urban area crossed by medium speed railway. We believe that the test of the new approach through the implementation of two different types of intervention of the acoustic reclamation is fully representative. The test enables to understand in detail the peculiarities of the innovative approach and its advantages compared to a traditional approach. In particular, the results of the different approaches on the weakness areas identified in the state of the art will be highlighted and discussed:

1. Opportunity to decide to take action to reduce the noise from any condition of acoustic discomfort felt by a community, regardless of a legislative compulsion;

2. Opportunity to choose different acoustics remediations in line with the adoption of the criterion of the minimum total cost for the community rather than the traditional criterion of the minimum cost (supported by those who have the obligation to make the intervention) for the intervention itself;

3. For the sake of a simple exemplification in the rest of the paper, the selected unit of analysis is shown in Fig. 3. It is $250 \mathrm{~m}$ wide (symmetrical) and $500 \mathrm{~m}$ long (to exemplify a standard housing area) and it was divided into two zones in accordance with the Italian Presidential Decree of 18 November, 1998, n. 459: Regulations for the execution of the art. 11, L. 447/1995, concerning noise pollution caused by rail traffic (Italian Official Gazette No. 2 of 4th Jan. 1999), of which we show articles 3 and 5.

Art. 3. Zone of relevance

1. From the center-line of the external rails and for each side, areas of relevance for the infrastructures are established with the following width:

a) $250 \mathrm{~m}$ for the existing infrastructures, for their variants and for the infrastructures that are newly built alongside the existing ones; infrastructure of new construction characterized by a train speed lower $200 \mathrm{~km} / \mathrm{h}$. This zone is divided into two parts: the first, large $100 \mathrm{~m}$, nearest to the infrastructure, named zone $A$; the second, large $150 \mathrm{~m}$, more distant from the infrastructure, named zone $B$;

Art. 5. Existing and newly constructed infrastructures with a design speed not exceeding $200 \mathrm{~km} / \mathrm{h}$

1. For existing infrastructures, their variants, infrastructures newly built alongside of existing infrastructures and for the infrastructures of new construction with a design speed not exceeding $200 \mathrm{~km} / \mathrm{h}$, within the range set out in Article 3, the absolute limit values of the noise produced by the infrastructure are the following:

a) $50 \mathrm{~dB}(\mathrm{~A})$ Leq daytime, $40 \mathrm{~dB}$ ( $A$ ) Leq night for schools, hospitals, nursing homes and retirement homes; for schools is valid only the daytime limit.

b) $70 d B(A)$ Leq daytime, $60 d B(A)$ Leq night for other receptors within the zone $A$, mentioned in Article 3.

c) $65 d B(A)$ Leq daytime, $55 d B(A)$ Leq night for other receptors within the zone $B$, mentioned in Article 3. 


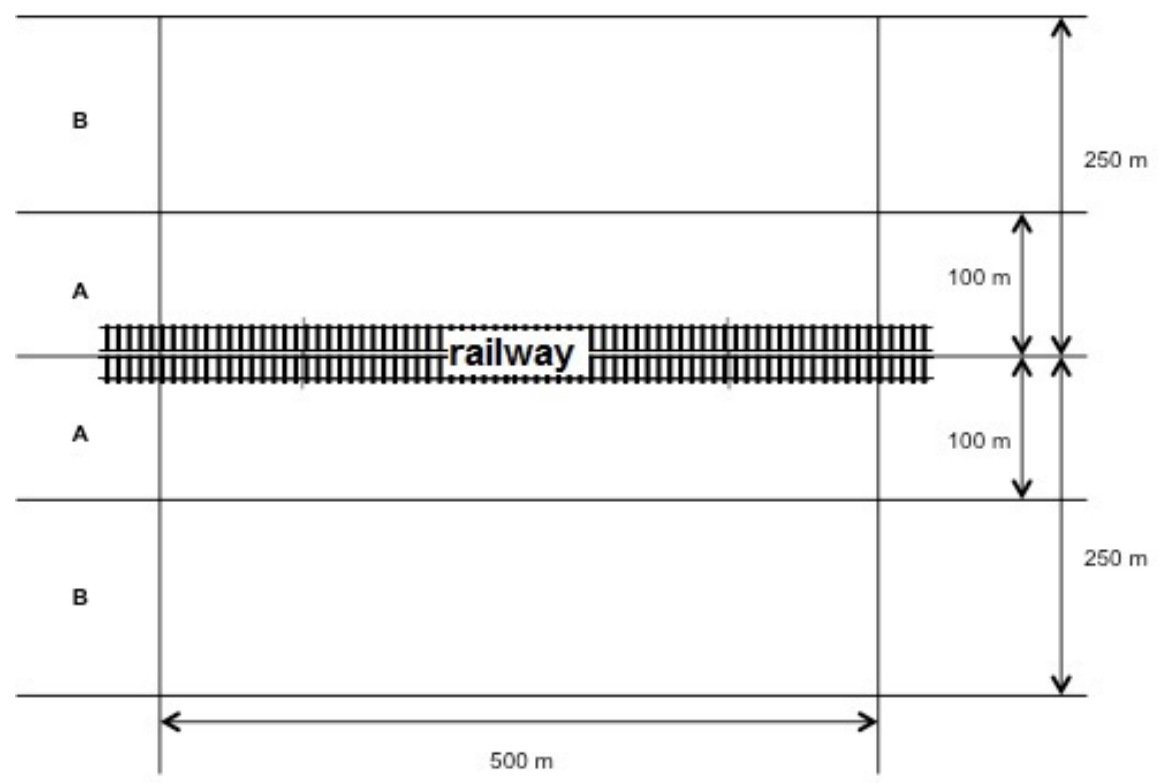

Fig. 3. Area of the case study and its splitting in zones

As regards the distribution of the buildings, refer to Fig. 4.

The zone taken into consideration is divided into two parts: the first, nearest to the infrastructure, of $100 \mathrm{~m}$ width, named zone A; the second, more distant from the infrastructure, of $150 \mathrm{~m}$ width, named zone $\mathrm{B}$.

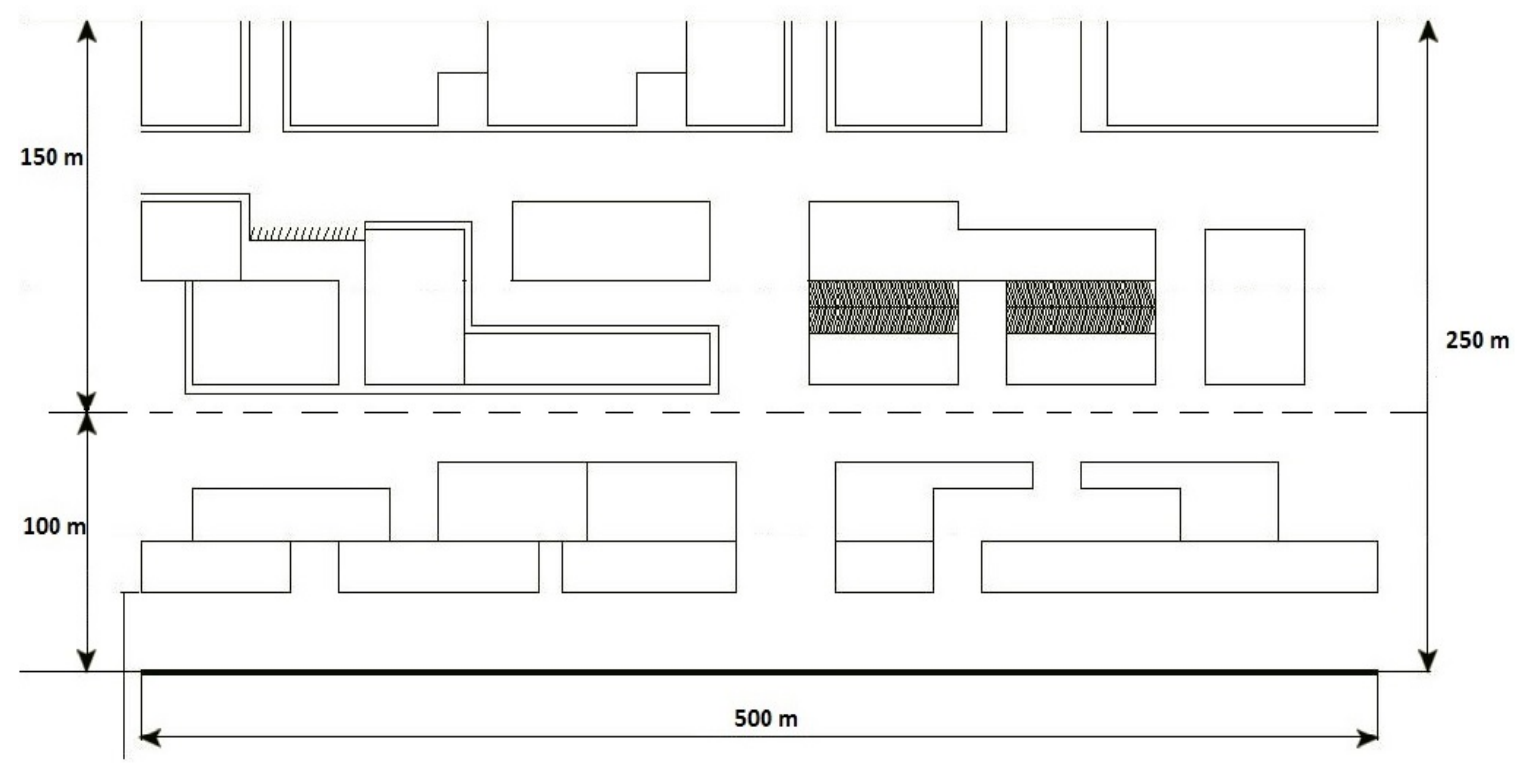

Fig. 4. Distribution of the buildings

The area of the land occupied by the residential buildings was considered (based on the average distribution of the buildings in an urban area densely populated) $51,200 \mathrm{~m}^{2}$, divided as follows between the two bands: 
Sector B (150 m): $60 \%$ of $51,200 \mathrm{~m}^{2}=30,720 \mathrm{~m}^{2}$

A reasonable assumption in the investigated area, can be that the buildings are on average composed of 5 floors and occupied by 1 person every $40 \mathrm{~m}^{2}$. The inhabitants of the various sectors will be distributed as follows:

$$
\begin{aligned}
& \text { Sector A: } 20,480 * 5 / 40=2,560 \\
& \text { Sector B: } 30,720 * 5 / 40=3,840
\end{aligned}
$$

for a total of 6,400 inhabitants

It is required to quantify the noise exposure of all the buildings along the railway line to determine the need and the size of an acoustics remediation. It was considered appropriate to avoid unnecessary costs of phonometric detection because the study is intended to provide a rough estimate of the benefit of an acoustic remediation. For this purpose, we have used a simulation of RFI (Italian Railway Network) that provides the sound power emitted per meter by any kind of train travelling at a speed of $100 \mathrm{~km} / \mathrm{h}$ in transit on the line [41]. We consider valid this value even if some overnight trains travel at a slower speed; clearly this assumption represents a worsening of the case study compared to the reality. The noise is mainly generated by the contact between wheel and rail and, the rails being a fixed element, the noise will depend on the kind of train that passes through the zone of interest; the simulation has enabled the grouping of the 30 types of commercial trains transiting through the Italian territory in 11 classes of trains called "j" (characterized by a homogeneous sound emission) presented in Table 1, of which we consider only those of the trains operating in the urban area exemplified later.

\begin{tabular}{|c|c|c|c|c|}
\hline $\begin{array}{l}\text { Noise } \\
\text { classes of } \\
\text { trains }\end{array}$ & $\begin{array}{l}\text { Indicative } \\
\text { length of } \\
\text { trains }\end{array}$ & Commercial codes of trains & $\begin{array}{l}\text { Power levels }\left[L_{w / m, j} \text { in } \mathrm{dB}(\mathrm{A}) / \mathrm{m}\right] \text { for each } \\
\text { octave band } \\
\text { Bands: } 63 \mathrm{~Hz} 125 \mathrm{~Hz} 250 \mathrm{~Hz} 500 \mathrm{~Hz} 1 \mathrm{kHz} \\
2 \mathrm{kHz} 4 \mathrm{kHz} 8 \mathrm{kHz}\end{array}$ & $\begin{array}{c}\text { Overall power } \\
\text { levels } \\
{\left[\mathrm{L}_{\mathrm{w} / \mathrm{m}, \mathrm{j}} \text { in } \mathrm{dB}(\mathrm{A}) / \mathrm{m}\right]}\end{array}$ \\
\hline 1 & 30 & diesel traction & 30.037 .647 .257 .358 .755 .051 .542 .5 & 62.7 \\
\hline 2 & 200 & $\mathrm{DIR} / \mathrm{IR}$ & 33.439 .151 .255 .560 .362 .657 .147 .8 & 66.3 \\
\hline 3 & 200 & E/EN & 37.049 .358 .363 .964 .264 .461 .052 .0 & 70.1 \\
\hline 4 & 300 & ETR450/460/480 & 28.432 .741 .445 .149 .959 .255 .044 .0 & 61.5 \\
\hline 5 & 300 & ETR 500 & 29.733 .744 .248 .653 .760 .354 .343 .7 & 62.5 \\
\hline 6 & 300 & IC & 33.337 .648 .552 .759 .464 .458 .248 .1 & 66.9 \\
\hline 7 & 80 & REG & 33.539 .751 .055 .558 .059 .955 .847 .7 & 64.4 \\
\hline 8 & 80 & TAF (REG-MET) & 28.437 .046 .452 .354 .654 .252 .045 .8 & 60.2 \\
\hline 9 & 550 & freight train & 40.250 .260 .368 .570 .569 .665 .656 .0 & 75.6 \\
\hline
\end{tabular}

Table 1. Acoustic classes of trains and related power levels 


\begin{tabular}{c|c|c|c|c}
\hline 10 & 30 & diesel traction & 35.547 .958 .763 .665 .462 .157 .747 .2 & 69.6 \\
\hline 11 & 80 & metropolitan & 35.344 .554 .558 .861 .660 .357 .649 .4 & 66.5 \\
\hline
\end{tabular}

By the number of transits per time slot (Tab. 5), it is possible to determine the average length of the trains in the two following slots:

$\rightarrow$ daylight exposure:

$(200 * 10+200 * 5+300 * 2+300 * 39+300 * 36+80 * 52+550 * 10) /(10+5+2+39+36+52+10)=$ $232.21 \mathrm{~m}$

$\rightarrow$ night exposure:

$(200+200 * 2+300 * 5+300 * 4+80 * 9+500 * 7) /(1+2+4+5+7+9)=268.57 \mathrm{~m}$

$\rightarrow$ So the average length will be:

$(23,221 * 16+26,857 * 8) / 24=586,392 / 24=24,433 m$

As we have taken into consideration standard but not precise lengths, which are variable by the number of wagons/coaches, we could consider acceptable an approximated average length of $250 \mathrm{~m}$ (which is equal to half of the considered stretch).

Knowing the power levels, it is possible to calculate the equivalent sound pressure level, given that the train, that is supposed to be $250 \mathrm{~m}$ long, can be considered something in between a linear and a point source (depending on the ratio length of the source/distance from the observer). However, starting from the data of the RFI simulation (i.e., sound power per unit length emitted by any kind of train in transit), the linear source is treated as a sequence of point sources: the linear source will be divided into 150 point sources, in which we suppose it is "concentrated" an equivalent length of $1.67 \mathrm{~m}$ and homogeneous as for the sound emission (which is consistent with the available data from RFI; see Table 1). According to this, if we multiply the specific acoustic power

$L_{\mathrm{w} / \mathrm{m}, \mathrm{j}} \mathrm{dB}(\mathrm{A}) / \mathrm{m}$

by the length of the various sources, we get the characteristic power (3) of every single point source "i" for any kind of train "j", expressed in $\mathrm{dB}(\mathrm{A})$ :

power of the point source $L_{\mathrm{w} / \mathrm{m}, \mathrm{ij}} \times 1.67 \mathrm{~dB}(\mathrm{~A})$

So it is possible to turn the sound power level of every single point source " $i$ " into the sound pressure level (4), being in conditions that can be assimilated to an open field (external environment, without walls or obstacles):

$L_{\mathrm{p} / \mathrm{m}, \mathrm{i}, \mathrm{j}}=L_{\mathrm{w} / \mathrm{m}, \mathrm{i}, \mathrm{j}} \mathrm{x} 1-8-20 \log \left(d_{\mathrm{i}, \mathrm{k}}\right) \mathrm{dB}(\mathrm{A})$

where $d_{i}$ is the average distance between the point source " $i$ " and the buildings taken into consideration, divided into "k" zones.

In order to determine the distances to take into consideration for the assessment of the equivalent level of sound pressure, we ground on some assumptions: 
1) The estimate must be conservative but simple to make in order to allow future replicability;

2) The train produces acoustic pressure certainly before arriving in correspondence of the minimum distance from the observer, but it is complex to estimate the entire equivalent exposure because we do not have the mathematical functional forms of $L p$; but, according to the first assumption, we deem more relevant the step of crossing in which at least one point of the train is facing the observer;

3) During the crossing phase mentioned in assumption 2, it is possible to highlight a phase of exposure increase (from the moment in which the head of the train is in correspondence with the observer to the moment in which the centre of the train is in correspondence with the observer, which is around $3 \mathrm{sec}$ ), a peak phase and a phase of decreasing (until the tail of the train is in correspondence with the observer). In practice, we consider only 9 seconds of "relevant" exposure or, in other words, the $9 \mathrm{sec}$ in which the train (250 $\mathrm{m}$ long) passes in front of the observer;

4) We suppose to associate the three phases of assumption 3 with a rough estimate of the contributions made on the distance between the observer and the middle of the train.

For the zone A (fig. 5):

phase 1: $d=135 \mathrm{~m}$; phase 2: $50 \mathrm{~m}$; phase 3: $135 \mathrm{~m}$

For the zone B (fig. 6):

phase 1: $d=215 \mathrm{~m}$; phase 2: $175 \mathrm{~m}$; phase 3: $215 \mathrm{~m}$

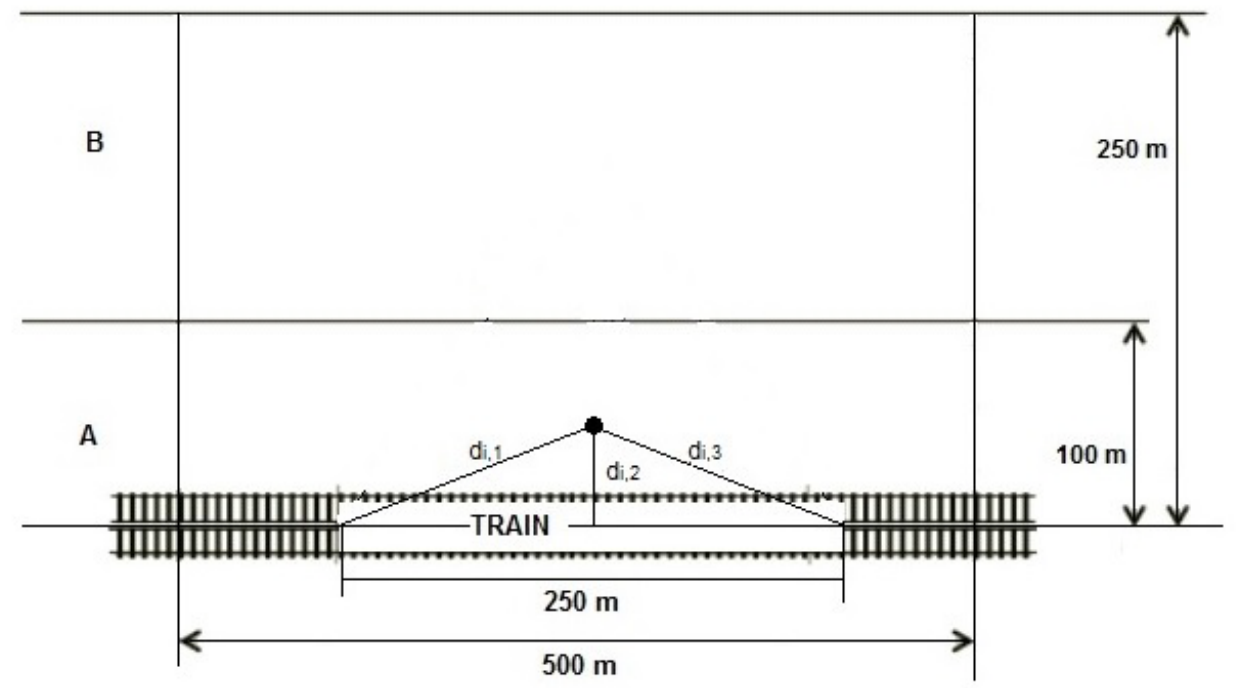

Fig. 5. Position of the observer in the zone $A$ 


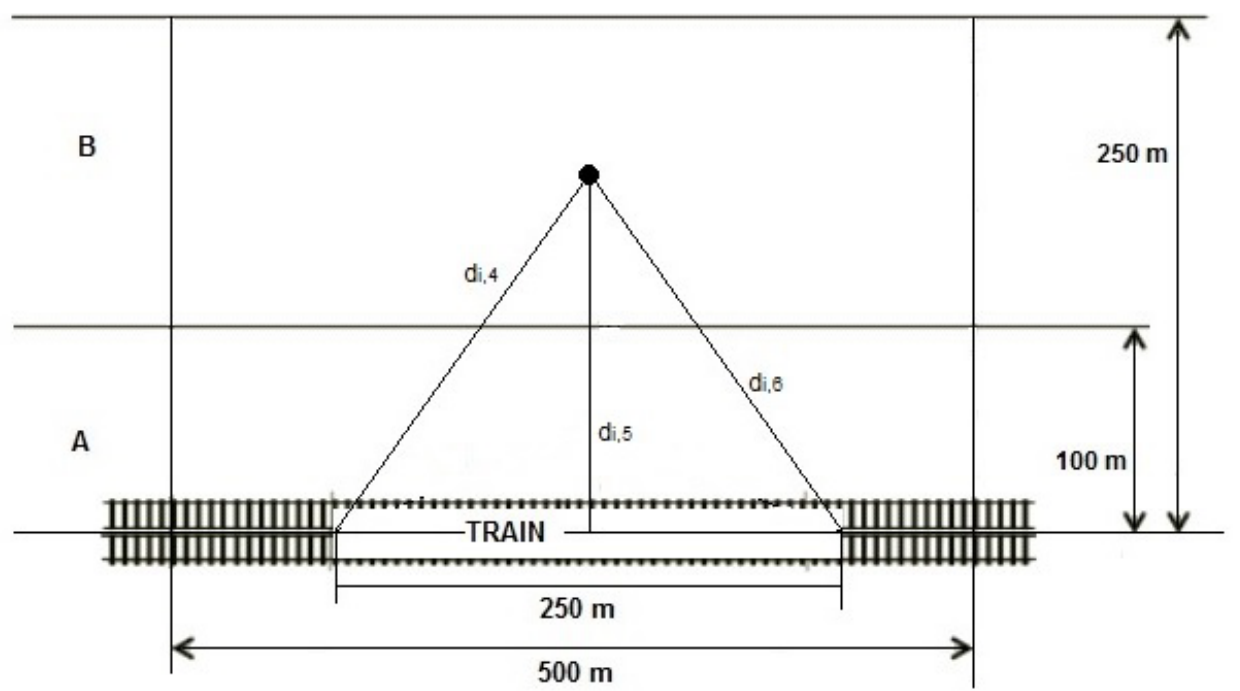

Fig. 6. Position of the observer in the zone $B$

Tables $2 \mathrm{~A}$ and $2 \mathrm{~B}$ present the detail of the quantifications for the two analyzed zones, as the sum of the contributions in frequency.

Table 2A. Levels of sound pressure related to every single point source "i" at the distances $d_{k}$ from rails (centre-lines of zone A)

\begin{tabular}{|c|c|c|c|c|c|}
\hline $\begin{array}{c}\text { Noise classes of } \\
\text { trains }\end{array}$ & $\begin{array}{c}\text { Commercial codes of } \\
\text { trains }\end{array}$ & $\begin{array}{l}\text { Power levels } \\
{\left[L_{w / m, j} \text { in } \mathrm{dB}(\mathrm{A}) / \mathrm{m}\right]}\end{array}$ & \multicolumn{3}{|c|}{$\begin{array}{l}\text { Levels of sound pressure related to every single } \\
\text { point source "i" at the distance } d_{i, k} \\
\qquad\left[L_{p, i, j} \text { in } \mathrm{dB}(\mathrm{A})\right]\end{array}$} \\
\hline & & & $d_{i, 1}=135 m$ & $d_{i, 2}=50 m$ & $d_{i, 3}=135 m$ \\
\hline 1 & diesel traction & 62.7 & 53.89 & 62.52 & 53.89 \\
\hline 2 & DIR/IR & 66.3 & 59.89 & 68.52 & 59.89 \\
\hline 3 & E/EN & 70.1 & 66.23 & 74.85 & 66.23 \\
\hline 4 & ETR 450/460/480 & 61.5 & 51.89 & 60.52 & 51.89 \\
\hline 5 & ETR 500 & 62.5 & 53.56 & 62.19 & 53.56 \\
\hline 6 & IC & 66.9 & 60.89 & 69.52 & 60.89 \\
\hline 7 & REG & 64.4 & 56.73 & 65.35 & 56.73 \\
\hline 8 & TAF (REG-MET) & 60.2 & 49.73 & 58.35 & 49.73 \\
\hline 9 & freight train & 75.6 & 75.39 & 84.02 & 75.39 \\
\hline 10 & diesel traction & 69.6 & 65.39 & 74.02 & 65.39 \\
\hline
\end{tabular}




\begin{tabular}{l|l|l|l|l|l}
\hline 11 & metropolitan & 66.5 & 60.23 & 68.85 & 60.23 \\
\hline
\end{tabular}

Table 2B. Levels of sound pressure related to every single point source " $i$ " at the distances $d_{k}$ from rails (centre-lines of the zone $B$ )

\begin{tabular}{|c|c|c|c|c|c|}
\hline \multirow[t]{2}{*}{$\begin{array}{c}\text { Noise classes of } \\
\text { trains }\end{array}$} & \multirow[t]{2}{*}{$\begin{array}{c}\text { Commercial codes of } \\
\text { trains }\end{array}$} & \multirow[t]{2}{*}{$\begin{array}{c}\text { Power levels } \\
{\left[L_{w / m, j} \text { in } \mathrm{dB}(\mathrm{A}) / \mathrm{m}\right]}\end{array}$} & \multicolumn{3}{|c|}{$\begin{array}{l}\text { Levels of sound pressure related to every } \\
\text { single point source "i" at the distance } d_{i, k} \\
\qquad\left[L_{p, i, j} \text { in } \mathrm{dB}(\mathrm{A})\right]\end{array}$} \\
\hline & & & $d_{i, 4}=215 m$ & $d_{i, 5}=175 m$ & $\mathrm{~d}_{\mathrm{i}, 6}=215 \mathrm{~m}$ \\
\hline 1 & diesel traction & 62.7 & 49.85 & 51.64 & 49.85 \\
\hline 2 & DIR/IR & 66.3 & 55.85 & 57.64 & 55.85 \\
\hline 3 & E/EN & 70.1 & 62.18 & 63.97 & 62.18 \\
\hline 4 & ETR 450/460/480 & 61.5 & 47.85 & 49.64 & 47.85 \\
\hline 5 & ETR 500 & 62.5 & 49.52 & 51.31 & 49.52 \\
\hline 6 & IC & 66.9 & 56.85 & 58.64 & 56.85 \\
\hline 7 & REG & 64.4 & 52.68 & 54.47 & 52.68 \\
\hline 8 & TAF (REG-MET) & 60.2 & 45.68 & 47.47 & 45.68 \\
\hline 9 & freight train & 75.6 & 71.35 & 73.14 & 71.35 \\
\hline 10 & diesel traction & 69.6 & 61.35 & 63.14 & 61.35 \\
\hline 11 & metropolitan & 66.5 & 56.18 & 57.97 & 56.18 \\
\hline
\end{tabular}

Applying the formula (6), it is possible to calculate the value of the equivalent pressure level at the distance $d_{1}=50 \mathrm{~m}$ and at the distance $d_{2}=175 \mathrm{~m}$.

$L_{\mathrm{p}, \mathrm{i}, \mathrm{j}, \mathrm{d}_{k}}=10 \log \left(10^{\frac{L_{\mathrm{p}, \mathrm{i}, \mathrm{j}}}{10}}+10^{\frac{L_{\mathrm{p}, \mathrm{i}, \mathrm{j}}}{10}}+10^{\frac{L_{\mathrm{p}, \mathrm{i}, \mathrm{j}}}{10}}\right) \mathrm{dB}(\mathrm{A})$

Table 3. Levels of sound pressure $L p, i, j, d_{k}[d B(A)]$, at a distance $d_{k}$

\begin{tabular}{|c|c|c|c|}
\hline \multirow[t]{2}{*}{$\begin{array}{c}\text { Noise classes of } \\
\text { trains }\end{array}$} & \multirow[t]{2}{*}{ Commercial codes of trains } & \multicolumn{2}{|c|}{$\begin{array}{c}\text { Levels of sound pressure, } \\
L p, i, j, d_{k}[\mathrm{~dB}(\mathrm{~A})], \text { at a distance } d_{k}\end{array}$} \\
\hline & & $d_{1}=50 \mathrm{~m}($ zone $\mathrm{A})$ & $d_{2}=175 \mathrm{~m}$ (zone B) \\
\hline 1 & diesel traction & 63.57 & 55.3 \\
\hline 2 & $\mathrm{DIR} / \mathrm{IR}$ & 69.57 & 61.3 \\
\hline
\end{tabular}




\begin{tabular}{c|c|c|c}
\hline 3 & E/EN & 75.91 & 57.64 \\
\hline 4 & ETR450/460/480 & 61.57 & 54.97 \\
\hline 5 & ETR 500 & 63.24 & 62.3 \\
\hline 6 & IC & 70.57 & 58.14 \\
\hline 7 & REG & 66.41 & 51.14 \\
\hline 8 & TAF (REG-MET) & 59.41 & 76.8 \\
\hline 10 & freight train & 85.07 & 66.8 \\
\hline 11 & diesel traction & 75.07 & 61.64 \\
\hline
\end{tabular}

It is now possible to add the contributions of the 150 point sources in which is divided the $\mathrm{j}$-th sound source "train", to get the corresponding level of the total sound pressure:

$L_{\mathrm{p}, \mathrm{j}, \mathrm{tot}}=10 \log \left(150 \times 10^{\frac{L_{\mathrm{p}, \mathrm{i}, \mathrm{d}}}{10}}\right) \mathrm{dB}(\mathrm{A})$

The final result is shown in Table 4.

Table 4. Levels of sound pressure $L p, j[d B(A)]$, at a distance $d_{k}$

\begin{tabular}{|c|c|c|c|}
\hline \multirow{2}{*}{$\begin{array}{c}\text { Noise classes of } \\
\text { trains }\end{array}$} & \multirow[t]{2}{*}{ Commercial codes of trains } & \multicolumn{2}{|c|}{ Levels of sound pressure $L_{p, j}[\mathrm{~dB}(A)]$, at a distance $d_{k}$} \\
\hline & & $d_{1}=50 \mathrm{~m}$ (zone $\left.A\right)$ & $d_{2}=175 \mathrm{~m}$ (zone B) \\
\hline 1 & diesel traction & 85.33 & 77.06 \\
\hline 2 & DIR/IR & 91.33 & 83.06 \\
\hline 3 & E/EN & 97.67 & 89.4 \\
\hline 4 & ETR450/460/480 & 83.33 & 75.06 \\
\hline 5 & ETR 500 & 85 & 76.73 \\
\hline 6 & IC & 92.33 & 84.06 \\
\hline 7 & REG & 88.17 & 79.9 \\
\hline 8 & TAF (REG-MET) & 81.17 & 72.9 \\
\hline
\end{tabular}




\begin{tabular}{c|c|c|c}
\hline 9 & freight train & 106.83 & 98.56 \\
\hline 10 & diesel traction & 96.83 & 88.56 \\
\hline 11 & metropolitan & 91.67 & 83.4 \\
\hline
\end{tabular}

It is possible to get the equivalent level of the sound pressure, knowing the following:

a) The time taken by a train to cover the $500 \mathrm{~m}$ of the concerned area,

b) The number of transits for every acoustic class of the trains.

The time taken by a point source to cover the $500 \mathrm{~m}$ of the concerned area can be estimated at approximately 18 seconds. The noise increases gradually when the train enters the concerned area and decreases gradually when it exits; as soon as the first point source overlooks the considered area, after 0.09 seconds the second point source arrives and so on; therefore, after $9 \mathrm{~s}$ all the 250 point sources (concentrated) will be present in the considered area, rising to the maximum value of noise, which will remain for another $9 \mathrm{~s}$, when the first point source will exit from the considered area. The trend of the noise therefore has a ramp that lasts $9 \mathrm{~s}$, then it remains at a constant value for $9 \mathrm{~s}$ and finally it decreases for another $9 \mathrm{~s}$. Although the overall duration of exposure lasts $27 \mathrm{~s}$, since the decrease compensates for the increase, it can be considered a constant emission of each train in transit equal to the maximum value for a duration of $18 \mathrm{~s}$. It is believed that this modeling is sufficiently realistic and appropriate to assess the overall exposure. The average number of transits was provided by RFI, and the data, divided into the daytime and nighttime, are presented in Table 5.

Table 5. Number of transits for hourly band

\begin{tabular}{|c|c|c|c|}
\hline \multirow{2}{*}{$\begin{array}{c}\text { Noise classes of } \\
\text { trains }\end{array}$} & \multirow[t]{2}{*}{ Commercial codes of trains } & \multicolumn{2}{|c|}{ Number of transits for hourly band } \\
\hline & & $\begin{array}{l}\text { daylight exposure } \\
\text { (h } 6.00 \div \mathrm{h} 22.00 \text { ) }\end{array}$ & $\begin{array}{l}\text { night exposure } \\
\text { (h } 22.00 \div \text { h 6.00) }\end{array}$ \\
\hline 1 & diesel traction & - & - \\
\hline 2 & $\mathrm{DIR} / \mathrm{IR}$ & 10 & 1 \\
\hline 3 & E/EN & 5 & 2 \\
\hline 4 & ETR 450/460/480 & 2 & - \\
\hline 5 & ETR 500 & 39 & 5 \\
\hline 6 & IC & 36 & 4 \\
\hline 7 & REG & 52 & 9 \\
\hline
\end{tabular}




\begin{tabular}{c|c|c|c}
\hline 8 & TAF (REG-MET) & - & - \\
\hline 9 & freight train & 10 & 7 \\
\hline 10 & diesel traction & - & - \\
\hline 11 & metropolitan & - & - \\
\hline
\end{tabular}

The level of the equivalent sound pressure, Leq, can be calculated by the formula (8):

$L_{\text {eq }}=10 \log \left(\frac{1}{T} \times \sum_{J=1}^{N}\left(10^{\frac{L_{\mathrm{p}, \mathrm{j}, \text { tot }}}{10}} \times t_{j}\right)\right) \mathrm{dB}(\mathrm{A})$

where:

$\rightarrow \mathrm{T}$ is the period of observation (day, night)

$\rightarrow t_{j}$ is the travel time of the $\mathrm{j}$-th train in the considered area during the period of observation

$\rightarrow L_{p, j, t o t}$ is the sound pressure level of the $\mathrm{j}$-th train during the period of observation

The level of equivalent pressure obtained for each individual band is presented in Table 6 .

Table 6. Equivalent level of sound pressure per band

\begin{tabular}{|c|c|c|}
\hline \multirow{2}{*}{ BAND OF RELEVANCE } & \multicolumn{2}{|c|}{$L_{e q(A), T}[\mathrm{~dB}(\mathrm{~A})]$} \\
\hline & Daylight exposure (h $6.00 \div \mathrm{h} 22.00$ ) & Night exposure (h $22.00 \div \mathrm{h} 6.00$ ) \\
\hline$A[0-100 \mathrm{~m}]$ & 79.96 & 80.57 \\
\hline$B[100-250 \mathrm{~m}]$ & 71.69 & 72.3 \\
\hline
\end{tabular}

\section{Results}

Following the evaluation of the quantitative exposure to the noise, and the observation of the acoustic discomfort inside the houses of the unit of analysis, the implementation of the innovative approach is presented.

\section{Step 1: Identification of possible disturbance due to noise.}

In addition to the comparison with the values of Table 7, the levels of the equivalent pressure for each individual band (Tab. 7) are compared with a general condition of acoustic wellbeing which allows a maximum value of 
noise exposure equal to $55 \mathrm{~dB}$ (see Fig. 1 [29]). If we compare the values, we can observe a clear situation of discomfort.

\section{Step 2: Calculation of the curve of the total cost of all the possible interventions.}

Once we have identified the opportunity to intervene, it is necessary to make a list that includes all the available interventions to reduce the noise. Due to the frequency of the utilization and its average cost, the analysis is focused on only two interventions:

1) Acoustic barriers;

2) Windows ventilated with high insulation.

Comparing the cost curves of the two considered interventions (Fig. 7), and given the needs in terms of noise reduction (up to $25 \mathrm{~dB}$ ), it is observed that the choice of the acoustic barriers is significantly more economic than the choice resulting from the ventilated windows with high insulation. For this reason, through the use of the traditional approach, the intervention of realization of the acoustic barrier as intervention of acoustic reclamation is chosen and accordingly implemented.

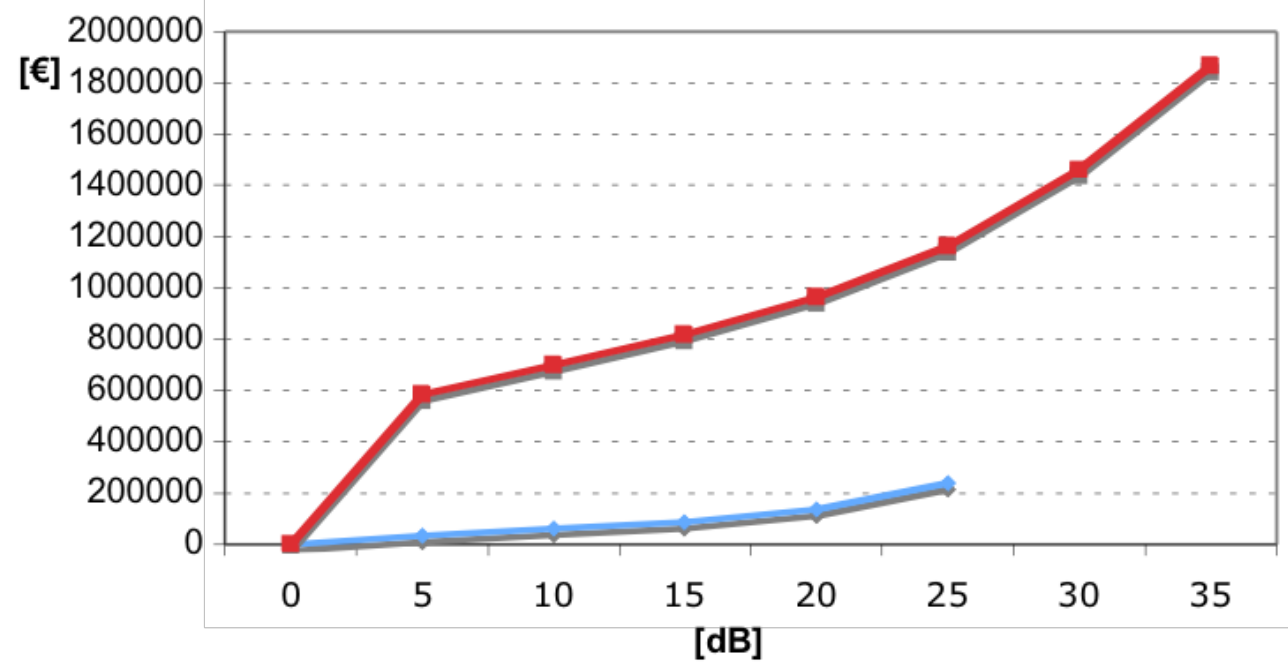

Legend:

cost of the barriers: -1 cost of the windows:

Fig. 7. Curve of the cost (expressed in $€$ ) attributed to the acoustic remediation, in function of the noise reduction

The evaluation of these two interventions has been made by calculating the curves of the total costs and taking into account both the cost of implementation of the intervention and the benefit resulting from the reduction of the noise. The benefit of the intervention from a social point of view has been assessed by the method of the hedonic prices [39]; it has been assessed through interviews with real estate agents, being equivalent to the depreciation of the buildings located in the area concerned by the acoustic discomfort, ceteris paribus (that is, the respondents have been explicitly asked to refer only to the portion of depreciation due to noise, possibly 
regardless additional problems often connected as view, safety, air quality; this was particularly crucial for the closest buildings, rather irrelevant for the remaining ones, i.e. the majority of them).

The evaluation result is shown in Fig. 8 and in Fig. 9.

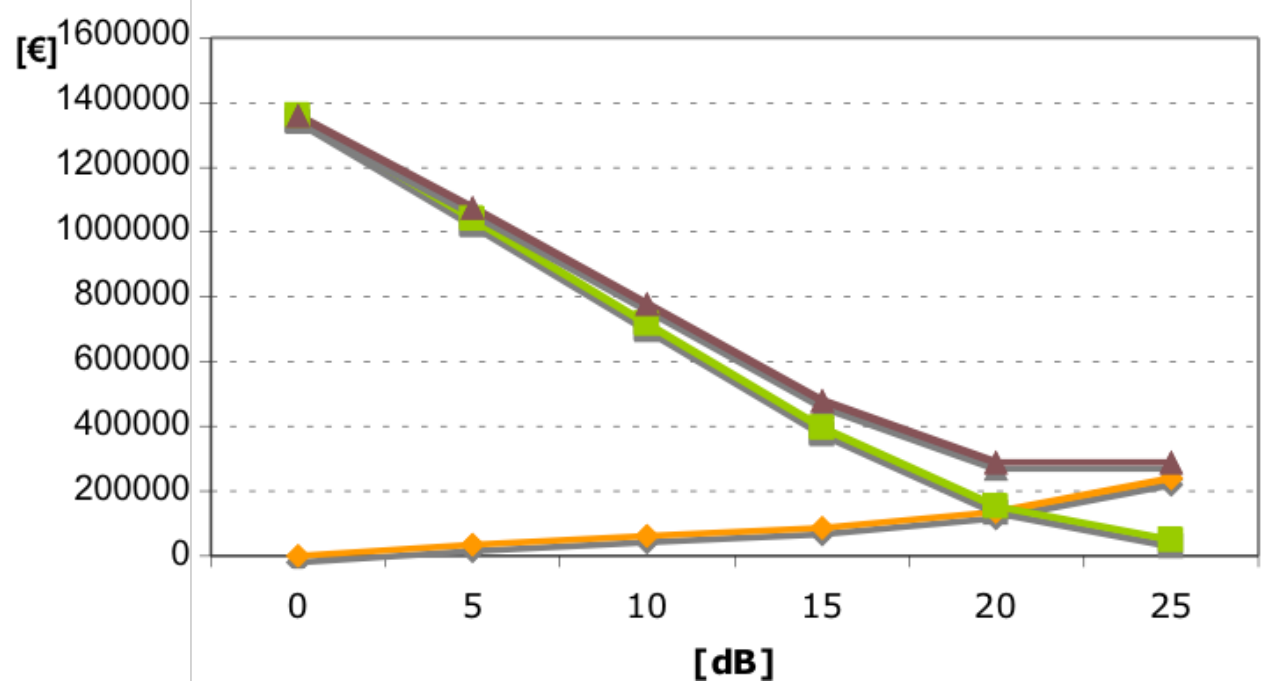

Legend:

cost of remediation: $\longrightarrow$ social cost: - total cost: -1

Fig. 8. Curve of the total cost (expressed in $€$ ) obtained by the use of the acoustics barrier in function of the noise reduction

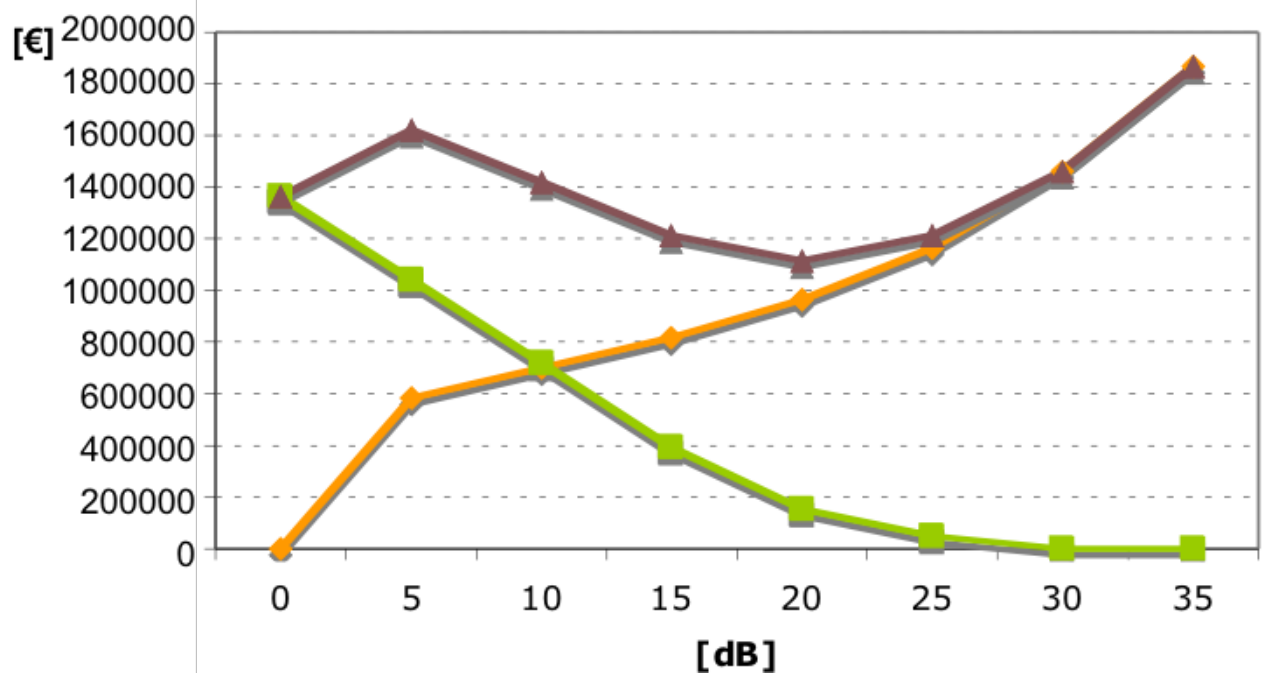

Legend:

cost of remediation: $\longrightarrow$ social cost: $-\longrightarrow$ total cost: -

Fig. 9. Curve of the total cost (expressed in $€$ ) obtained by the use of ventilated windows, in function of the noise reduction

Step 3: Identification of the best opportunity for intervention. 
The curve of the total cost related to the acoustic barrier has its minimum point in correspondence with a reduction of $25 \mathrm{~dB}$, with a total cost that is equal to $€ 288,971$.

The curve of the total cost related to the ventilated windows with a high insulation has instead its minimum point of correspondence with a reduction of $20 \mathrm{~dB}$, corresponding to a total cost that is equal to $€ 1,114,905$. Comparing the total cost curves (Figs. 8 and 9) as a selection criterion proposed by the innovative approach, the choice falls on the acoustic barriers. This implies the immediate knowledge of the dimensional characteristics of the barrier that minimizes the total cost, determined under construction of the total cost curve:

- $500 \mathrm{~m}$ in length (i.e., the length of the area concerned; adjacent areas are, in turn, considered as protected by barriers $500 \mathrm{~m}$ long);

- $7 \mathrm{~m}$ in height.

\section{Step 4: Comparison between the intervention with the lowest total cost and the current legislation.}

Since the choice has fallen on the acoustic barrier with a reduction of $25 \mathrm{~dB}$, the values of the equivalent noise levels become the following (Tab. 7).

Table 7. Equivalent sound levels divided in bands after the acoustics intervention selected by the innovative approach

\begin{tabular}{|c|c|c|}
\hline \multirow[b]{2}{*}{ BAND OF RELEVANCE } & \multicolumn{2}{|c|}{$L_{e q(A), T}[\mathrm{~dB}(\mathrm{~A})]$} \\
\hline & $\begin{array}{l}\text { Daylight exposure } \\
\text { (h } 6.00 \div \text { h } 22.00 \text { ) }\end{array}$ & $\begin{array}{l}\text { Night exposure } \\
\text { (h } 22.00 \div \text { h } 6.00 \text { ) }\end{array}$ \\
\hline$A[0-100 \mathrm{~m}]$ & $54.6 \mathrm{~dB}(\mathrm{~A})$ & $55.2 \mathrm{~dB}(\mathrm{~A})$ \\
\hline$B[100-250 \mathrm{~m}]$ & $47.0 \mathrm{~dB}(\mathrm{~A})$ & $47.6 \mathrm{~dB}(\mathrm{~A})$ \\
\hline
\end{tabular}

The comparison between the values of Table 7 and the absolute limit values of the input (Tab. 6) highlights that in the unit of analysis of the case study, after the intervention of acoustic reclamation, the limit values are respected in all segments.

Step 5: Implementation of the chosen intervention.

The operation can be realized.

\section{Sensitivity analysis}

In order to identify any unexpected fluctuations in the results of the approach in terms of the critical variables that can affect the choice of the means of the intervention, a sensitivity analysis has been carried out. 
In the presented case study, the following variables seem to be quite significant:

$\rightarrow$ Total extension of the buildings in the unit of analysis;

$\rightarrow$ Level of the traffic rail on which the equivalent sound pressure levels depend;

$\rightarrow$ Cost of the acoustics barriers.

Assuming a change of the dimensions of the housing of the $20 \%$, we obtain the total cost curves shown in Fig. 10.

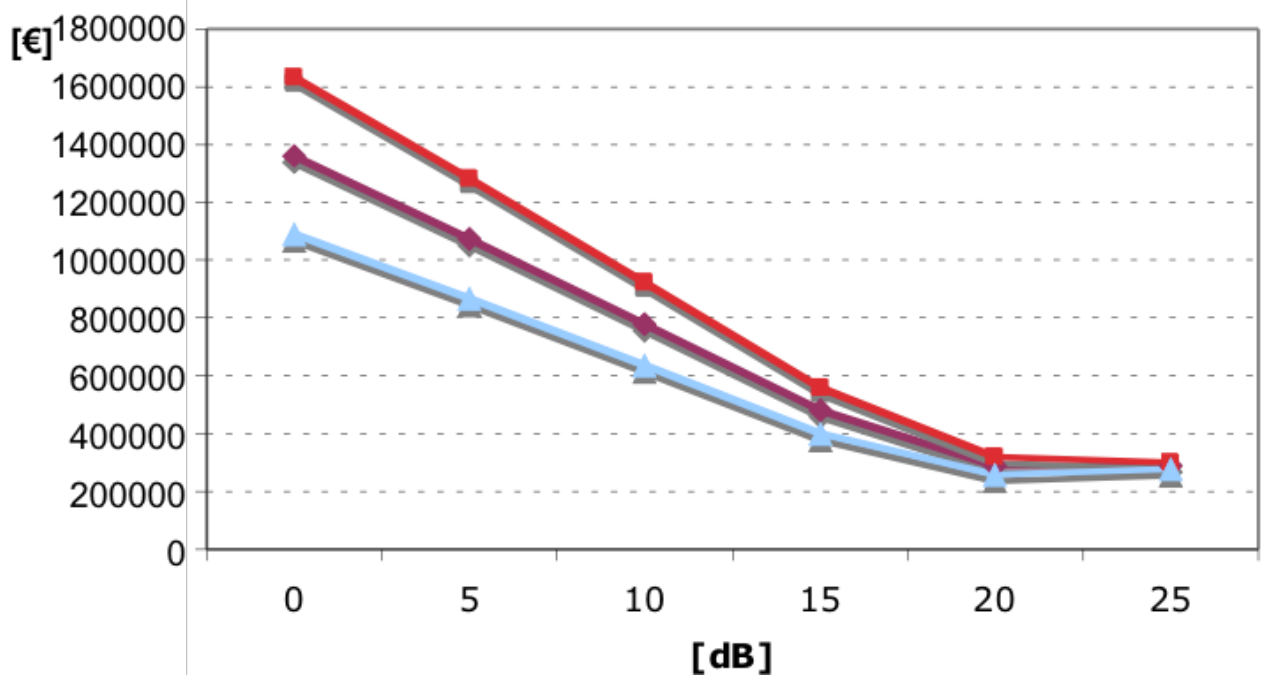

Legend:

total cost: - total cost (flat $+20 \%):-\quad$ total cost (flat $-20 \%)$ :

Fig. 10. Curves of total cost (expressed in $€$ ) at the variation of the flat dimensions.

These curves have their lowest point corresponding to the following values:

$\rightarrow$ Total cost: reduction of $25 \mathrm{~dB}$ with a cost of $€ 288,971$;

$\rightarrow$ Total cost (+20\%): reduction of $25 \mathrm{~dB}$ with a cost of $€ 298,885$;

$\rightarrow$ Total cost (- 20\%): reduction of $20 \mathrm{~dB}$ with a cost of $€ 279,057$.

Assuming a change of the rail traffic level by $10 \%$, we obtain the total cost curves represented in Fig. 11 . 


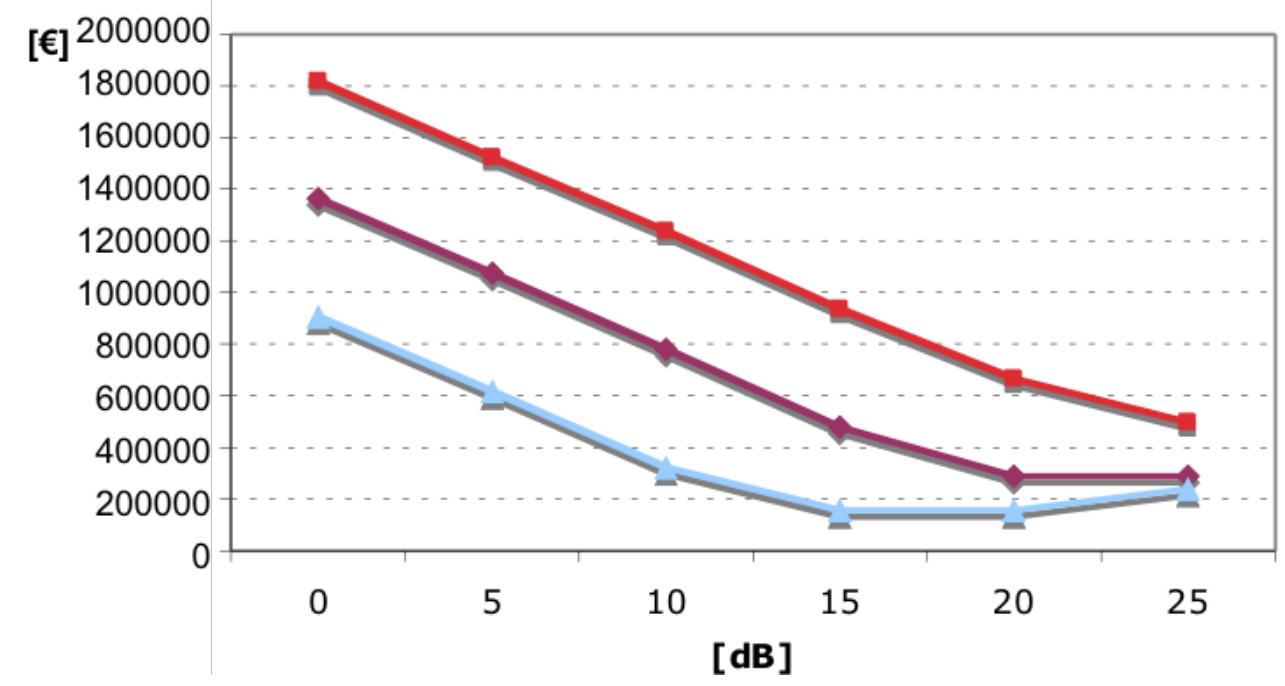

Legend:

total cost: $\longrightarrow$ total cost (traffic $+10 \%):-\quad$ total cost (traffic $-10 \%$ ):

Fig. 11. Curves of total cost at the variation of the rail traffic level.

These curves have their lowest point corresponding to the following values:

$\rightarrow$ Total cost: reduction of $25 \mathrm{~dB}$ with a cost of $€ 288,971$;

$\rightarrow$ Total cost (+ 10\%): reduction of $25 \mathrm{~dB}$ with a cost of $€ 496,729$;

$\rightarrow$ Total cost (- 10\%): reduction of $20 \mathrm{~dB}$ with a cost of $€ 155,389$.

Assuming a change of the cost of the acoustic barriers of $20 \%$, we obtain the total cost curves represented in Fig. 12.

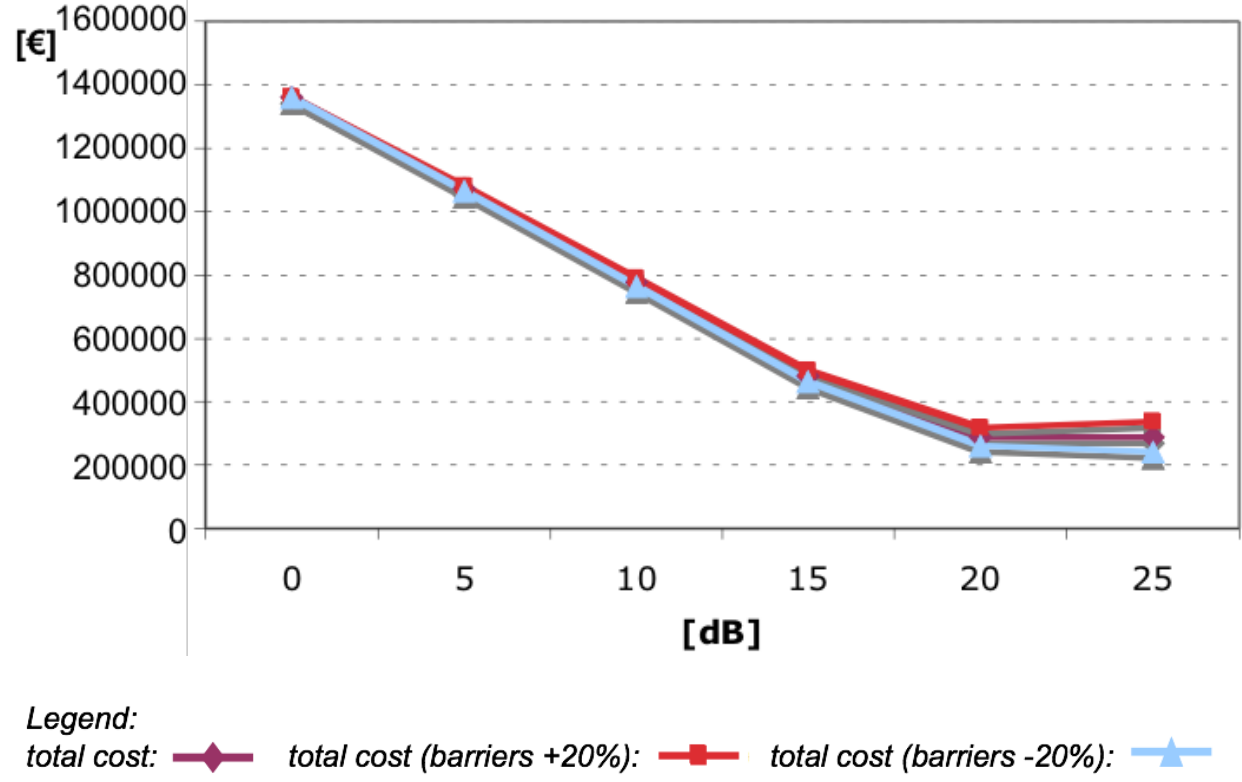

Fig. 12. Curves of total cost at the variation of the cost of the acoustic barriers 
These curves have their lowest point corresponding to the following values:

$\rightarrow$ Total cost: reduction of $25 \mathrm{~dB}$ with a cost of $€ 288,971$;

$\rightarrow$ Total cost (+20\%): reduction of $20 \mathrm{~dB}$ with a cost of $€ 316,351$;

$\rightarrow$ Total costs (- 20\%): reduction of $25 \mathrm{~dB}$ with a cost of $€ 241,091$.

Comparing the three sensitivity analyses, it is evident that the critical variable is the level of the rail traffic as limited variations of it determine consistent variations of the parameters used in the analysis of the total cost taking the minimum point to a cost of $€ 496,729$ in case of a $10 \%$ increase of rail traffic and to a cost of $€ 155,389$ in case of a $10 \%$ reduction. However, the approach is valid to propose an abatement intervention bigger or equal to $20 \mathrm{~dB}$.

If we look at the results obtained in the case study using the two different approaches (traditional and innovative), we can observe that:

1) As we could imagine, considering only the cost of the curves, we have cost curves lower than those built on the total costs. This is evident as the innovative approach aims at considering also the social costs of the noise for a more accurate analysis;

2) The innovative approach based on the use of the total cost curve enables to get a more detailed solution with a minimum commitment of resources. To get this, the real estate depreciation of the buildings located in noisy areas is included in the social cost of the noise. Moreover, if we calculate the total cost curve, we get the intervention most convenient for the entire community on the basis of specific local features (and not just based on the threshold values of the legislation);

3) From a practical point of view, the innovative approach, once the type of intervention has been established, gives also a detailed indication on how to make the intervention. Actually, just in the point where the total cost curve has a minimum, you can identify the optimal abatement expressed in $\mathrm{dB}$. Starting from this abatement, it is possible to determine precisely the extent of the intervention to be carried out (barrier height, type of windows etc.).

As far as the uncertainty of the results is concerned, there is a twofold issue.

On the one hand, the exact value of the optimal abatement expressed in $\mathrm{dB}$ cannot be determined, which is in fact not the scope of the paper: the paper is rather aimed at identifying a reasonable range of values that significantly improve the living conditions of the community. This range has to be interpreted wisely by the decision makers, and given the shape of the curves provided, can be rather easily identified and agreed.

On the other hand, we estimate that the range within which the minimum value is positioned can be considered definitely restricted because of the reduced size of the urban area covered by the study (500 meters along the railway, 250 meters of adjacencies); and this will always happen in case of application of the decision approach to areas where the parameters uniformity (positional characteristics, constructions, amenities, etc.) is proper enough. Of course, this implies little generalization on the "values" nationwide or even region-wide, that is, in case there is no remarkable parameters uniformity (positional characteristics, constructions, amenities, etc.) 
of the real estate external to the perimeter of study. Summing up, a clusterization of areas would be necessary in order to generalize our results nationwide or region-wide, so as to implement the proposed approach to comparable areas (which could, in principle, be characterized by different optimal noise exposure and kind of intervention).

In the conclusion, then, we refer to "community" as the number of people experiencing a comparable (positional characteristics, constructions, amenities, etc.) situation in terms of areas they live in.

\section{Discussion and conclusions}

In conclusion, we can say that the study carried out has allowed us to define a new and innovative approach to determine, through the total cost curve, a noise abatement intervention good for the community. The traditional approach, shown in the shaded portion of Fig. 1, addresses the problem of noise pollution from a purely regulatory compliance. It measures, in fact, the pressure levels equivalent to each zone exposed to noise, and compares them with those limits set by the Presidential Decree of 18 November, 1998. Any intervention, resulting in such measures, only relates to the installation of sound barriers, because they remain the property of the railway company, while other interventions, such as the insulated windows, would remain the property of the exposed population. Conversely, the innovative approach starts from a situation of distress of the exposed population: that discomfort may be due to an annoying noise and/or to the depreciation of buildings in the area. Then it analyzes the boundary conditions, the applicable legislation and the existing and available interventions, and thus identifies several possible forms of acoustics remediation. Due to the frequency of utilization and its average cost, our case study has been focused on only two interventions:

1) Acoustic barriers,

2) Insulated windows.

The results of the innovative method put in evidence that the total cost curve related to the acoustic barrier is considerably lower than that of the windows with a high insulation, and that the point of maximum benefit for the community can be reached by breaking down $20 \mathrm{~dB}$ in the case of the windows and $25 \mathrm{~dB}$ in the case of the barrier. Anyway, the choice of the acoustic barrier is significantly more economical than the resulting ventilated windows of high-insulation.

The definition of an innovative approach and its application in a real case have enabled to overcome the limitations of the traditional approaches:

$\rightarrow$ In case the conditions of the acoustic discomfort are not out of the limits imposed by the legislation, no interventions are considered necessary;

$\rightarrow$ The choice of the way to make the intervention (based only on its cost);

$\rightarrow$ The lack of guidance on how to intervene.

Actually, the previous approaches took into consideration only the cost of the interventions necessary to fulfill the law requirements, without considering other factors such as the minor annoyance of the people and its social cost. Finally, the previous approach, once the intervention to be taken was decided, did not specify anything about the size, the structure and the level of the reduction. In summary, the innovative approach 
proposes the overcoming of the legislative approach in the railway sector in favour of methods based on finding a trade-off between costs and benefits of the intervention [15-17].

\section{References}

[1] Bluhm G, Nordling E. Health effects of noise from railway traffic-the HEAT study. Inter-Noise; 2005.

[2] Kihlman T. Developments in environmental noise policies. Proceedings of Forum Acusticum; Paper 964-0; 2005; Budapest. p. 35-40.

[3] Lundström A, Jäckers-Cüppers $M$, Hübner $P$. The new policy of the European Commission for the abatement of railway noise. J Sound Vib 2003;267:397-405.

[4] Kalivoda M, Danneskiold-Samso U, Kruger F, Bariskow B. EURailNoise: a study of European priorities and strategies for railway noise abatement. J Sound Vib 2003;267:387-396.

[5] European Commission. Future noise policy_European Commission green paper. Report COM(96) 540. Final report. European Commission, Brussels, Belgium; 1996.

[6] European Environment Agency. Indicator 4 - Traffic noise: exposure and annoyance-Are we moving in the right direction? Indicators on transport and environmental integration in the EU: TERM 2000; 2000.

[7] den Boer LC, Schroten A. Traffic noise reduction in Europe. CE Delft; 2007.

[8] Saremi M, Grenèche J, Bonnefond A, Rohmer O, Eschenlauer A, Tassi P. Effects of nocturnal railway noise on sleep fragmentation in young and middle-aged subjects as a function of type of train and sound level. Int J Psych 2008;70(3):184191.

[9] WHO Regional Office for Europe. NIGHT NOISE GUIDELINES FOR EUROPE; 2009.

[10] Tassi P, Rohmer O, Bonnefond A, Margiocchi F, Poisson F, Schimchowitsch S. Long term exposure to nocturnal railway noise produces chronic signs of cognitive deficits and diurnal sleepiness. J Env Psych 2013;33(March):45-52

[11] WHO European Centre for Environment and Health. Quantifying burden of disease from environmental noise: Second technical meeting report. Bonn; 2005

[12] Schultz TJ. Synthesis of social surveys on noise annoyance, J Acoust I Soc Am 1978;64(2):377-405.

[13] (Italian Directive) Direttiva, 25 Giugno 2002, n. 2002/49/CE, G. U. CE 18 Luglio 2002, n. L 189.

[14] (Italian Law) Legge Quadro, 26 Ottobre 1995, n. 447, S.O. alla G.U., 30 Ottobre 1995, n. 254.

[15] Oertli, J. Cost-benefit analysis in railway noise control, J Sound Vibr 2000;231:505-509.

[16] Elbers, FBJ. Consequences of noise creation quotas for railway in the Netherlands, NS Technisch Onderzoek; 1998.

[17] Boer L., Beek A. Low noise trains in broad perspective, KPMG and NS Technisch Onderzoek; 1999.

[18] Oertli J. Cost-benefit analysis in railway noise control. J Sound Vib 2000;231(3):505-509.

[19] de Vos P. How the money machine may help to reduce railway noise in Europe. J Sound Vib 2003;267(3):439-445.

[20] ISO. ISO/TS 15666 acoustics-assessment of noise annoyance by means of social and socio-acoustic surveys. Technical report, ISO; 2003.

[21] European Communities. Position paper on dose response relationships between transportation noise and annoyance. Technical report. Office for Official Publications of the European Communities, Luxembourg; 2002; ISBN 92-894-3894-0. 
[22] Miedema HME, Oudshoorn CGM. Annoyance from transportation noise: relationships with exposure metrics DNL and DENL and their confidence intervals. Environ Health Perspect 2001;109(4):409-416.

[23] Andersson $\mathrm{H}$, Ögren $\mathrm{M}$. Noise charges in rail infrastructure: a pricing schedule based on the marginal cost principle. Transp Policy 2007;14(3):204-213.

[24] Nelson JP. Hedonic property values of studies of transportation noise: aircraft and road traffic. In: Baranzini A, Ramirez $\mathrm{J}$, Schaerer $\mathrm{C}$, Thalmann $\mathrm{P}$, editors. Hedonic methods in housing markets: pricing environmental amenities and segregation, Springer, p. 57-82; 2008.

[25] Nelson JP. Airports and property values. A survey of recent evidence. J Transp Econ Policy 1980;14(1):37-52.

[26] Bickel P, Friedrich R, Burgess A, Fagiani P, Hunt A, Jong GD, Laird J, Lieb C, Lindberg G, Mackie P, Navrud S, Odgaard T, Ricci A, Shires J, Tavasszy L. Proposal for harmonized guidelines. Deliverable 5, HEATCO (Developing Harmonised European Approaches for Transport Costing and Project Assessment); 2006.

[27] Rosen S. Hedonic prices and implicit markets: product differentiation in pure competition. J Polit Econ 1974;82(1):3455.

[28] Babisch W. Cardiovascular effects of noise. Noise Health 2001;13(52):201.

[29] Brons M, Nijkamp P, Pels E, Rietveld P. Railroad noise: economic valuation and policy. Transp Res Part D: Transp Env 2003;8(3):169-184.

[30] Oertli J, Wassmer D. Rail noise control in Switzerland: legislation, environment, politics and finances. J Sound Vibr 1996;193(1):403-406.

[31] Stansfeld SA, Matheson MP. Noise pollution: non-auditory effects on health. British Med Bull 2003;68(1):243-257.

[32] Swinburn TK, Hammer MS, Neitzel RL. Valuing quiet: an economic assessment of US environmental noise as a cardiovascular health hazard. Amer J Prev Med 2015;49(3):345-353.

[33] DEFRA - Department for Environment, Food \& Rural Affairs, "Valuing impacts on: sleep disturbance, annoyance, hypertension, productivity and quiet." DEFRA, UK Government, 2014. A report informed by: the Interdepartmental Group on Costs and Benefits Noise Subject Group, available online @ www.gov.uk/noise-pollution-economic-analysis, last access on 2016, May 18.

[34] Office for National Statistics. Statistical bulletin - Families and Households: 2015 available online @ www.ons.gov.uk/peoplepopulationandcommunity/birthsdeathsandmarriages/families/bulletins/familiesandhouseholds/20 $\underline{15-11-05}$, last access on 2016, May 18.

[35] Passchier-Vermeer W, Passchier WF. Noise exposure and public health. Env Health Persp, 2000;108, Suppl 1:12331.

[36] Maris, E. The social side of annoyance [doctoral thesis]. Department of Social and Organisational Psychology/Cognitive Psychology, Faculty of Social and Behavioural Sciences, Leiden University; 2008.

[37] Delucchi MA, Hsu S. The external damage cost of direct noise from motor vehicles, Report \#1 in the series: The Annualized Social Cost of Motor-Vehicle Use in the United States, based on 1990-1991 data. Institute of Transportation Studies, University of California, Davis; 1996.

[38] Maddison D. Valuing changes in life expectancy in England and Wales caused by ambient concentrations of particulate matter. Int. Symp. "Externalities in the Urban Transport. Assessing and reducing the Impact"; October 1998; Milan, 27-29.

[39] Camagni R. Valutazione dell'impatto economico territoriale dell'interramento della ferrovia nel comune di Trento. Milano, Italy; CSE Centro Studi economici, 2004. 
[40] Yin RK. Case study research: design and methods. Thousand Oaks, CA; Sage, 1994.

[41] (Italian Report) Agenzia Regionale per la Protezione dell'Ambiente (ARPA). Rapporto sullo Stato dell'Ambiente in Lombardia; 2001; par 323. 